\title{
Relationship and Task Conflict at Work: Interactive Short-Term Effects on Angry Mood and Somatic Complaints
}

\author{
Laurenz L. Meier \\ University of South Florida \\ Paul E. Spector \\ University of South Florida
}

\author{
Sven Gross \\ University of Bern \\ Norbert K. Semmer \\ University of Bern
}

\begin{abstract}
Our research examined short-term within-person effects of relationship and task conflict on angry mood and somatic complaints. We assumed that conflicts of both kinds would be prospectively related to both indicators of impaired well-being, that the effect of relationship conflict would be stronger than the effect of task conflict, and that the effect of relationship conflict would be stronger when task conflict is low than when it is high. We tested our hypotheses with a daily diary study with ratings made 3 times/day for 2 weeks, involving 131 participants. We found a prospective main effect of relationship conflict on angry mood, but not on somatic complaints. In contrast, controlling for relationship conflict, task conflict was unrelated to both angry mood and somatic complaints. Supporting our assumption, task conflict moderated the effect of relationship conflict. Relationship conflict had a prospective effect on angry mood and somatic complaints that lasted until the next day if, and only if, task conflict was low.
\end{abstract}

Keywords: relationship conflict, task conflict, well-being, diary study

Work conflict is a vital research topic because of its link to both employee performance and well-being. An important distinction shown for performance (cf. De Dreu \& Beersma, 2005), but generally ignored for well-being, is between relationship conflict and task conflict. Relationship conflict refers to disagreements that are associated with feelings of animosity, and task conflict refers to disagreements about the correct way to solve a problem (see Jehn, 1995; Pinkley, 1990). Whereas there seems to be consensus that relationship conflict is uniformly dysfunctional, opinions vary about task conflict, with some arguing that it can have positive effects on performance (e.g., Jehn, 1995; Tjosvold, 2008) and should even be encouraged (Pondy, 1992; Van de Vliert \& De Dreu, 1994), but others focusing on negative effects (e.g., De Dreu, 2008). Given the importance of conflict, it is important to investigate whether task conflict has the same detrimental effects on well-being as relationship conflict. Moreover, previous research largely has neglected that level of task conflict is likely to alter the effect of relationship conflict (a sole exception being Guerra,

Laurenz L. Meier, Department of Psychology, University of South Florida; Sven Gross, Department of Psychology, University of Bern; Paul E. Spector, Department of Psychology, University of South Florida; Norbert K. Semmer, Department of Psychology, University of Bern, Switzerland.

This research was supported by Swiss National Science Foundation Grant PA00P1-131482 to Laurenz L. Meier. We thank Céline Mühlethaler for her help in the data collection.

Correspondence concerning this article should be addressed to Laurenz L. Meier, Department of Psychology, University of Fribourg, Rue de Faucigny 2, 1700 Fribourg, Switzerland. E-mail: laurenz.meier@unifr.ch
Martínez, Munduate, \& Medina, 2005). Furthermore, two additional limitations characterizing most conflict research need to be addressed. First, most studies have used cross-sectional designs, which shed little light on the direction of the effects (for an overview, see Spector \& Bruk-Lee, 2008). Second, most studies have assessed conflict as a chronic work condition, as opposed to investigating conflict episodes and their immediate effects (exceptions are Hahn, 2000; Ilies, Johnson, Judge, \& Keeney, 2011). In this article, we describe a study that addresses these issues.

\section{Relationship Conflict and Task Conflict}

People are in conflict when they feel obstructed by another person (Van de Vliert, 1997) and conflict may involve relationship-oriented or task-oriented dissent (e.g., Jehn, 1995; Pinkley, 1990). Task conflict refers to disagreements about the work to be done (e.g., differences of opinion or ideas about the correct way to approach a task), whereas relationship conflict refers to interpersonal disagreements regarding personal issues that are usually associated with feelings of animosity. In task conflict, the cause of the conflict tends to be attributed to situational factors, whereas relationship conflict is attributed to factors associated with the conflict partner or the relationship between the partners (Jehn, 1995).

\section{Existing Studies on the Effect of Conflict on Well-Being}

A large body of research has shown that conflict at work is negatively related to well-being (Spector \& Bruk-Lee, 2008). The large majority of this research, however, did not differentiate 
between task and relationship conflict. As a consequence, Spector and Bruk-Lee (2008) noted that empirical support for the assumption of detrimental effects of work conflict on well-being mainly comes from studies that operationalized conflict as relationship conflict; thus, studies on task conflict are mainly lacking. Crosssectional studies consistently have shown negative correlations between relationship conflict and both psychological well-being (e.g., negative affect) and somatic complaints (De Dreu, Van Dierendonck, \& De Best-Waldhober, 2003; Friedman, Tidd, Currall, \& Tsai, 2000; Giebels \& Janssen, 2005; Guerra et al., 2005), but results for task conflict are less clear. Bivariately, task conflict was negatively correlated with psychological well-being in the studies by Friedman et al. (2000), Guerra et al. (2005), and in Study 3 of De Dreu et al. (2003), but it was unrelated to somatic complaints in Studies 1 and 2 of De Dreu et al. It should be noted, however, that only two studies examined the independent effects of relationship and task conflict on psychological well-being; in both, the effect of relationship conflict was retained, whereas findings for task conflict were mixed. Controlling for relationship conflict, task conflict was significantly related to psychological well-being in Guerra et al. but not in Giebels and Janssen (2005). Neither study investigated somatic complaints. In sum, findings about the independent effects of task and relationship conflict are sparse and mixed regarding psychological well-being as an outcome and completely lacking for somatic complaints. In the present study, we tested the independent effect of both task and relationship conflict on angry mood as an indicator of psychological well-being and on somatic complaints.

\section{Independent Effects of Relationship and Task Conflict}

Conflicts obstruct the achievement of goals, including specific task-related goals, such as solving a problem, as well as more general goals, such as being a competent and socially accepted person. According to Lazarus (1999), threats to goals trigger negative emotions and hence are perceived as stressful. Relationship conflict signals a lack of respect and includes expressions of interpersonal tension and rejection; thus, it threatens the fundamental goal of belonging to significant groups and maintaining good interpersonal relationships (see Baumeister \& Leary, 1995; De Dreu \& Gelfand, 2008). More generally, it is a threat to self-esteem and social esteem, which is particularly stressful, leading to lowered well-being (Lazarus, 1999; cf. Semmer, Jacobshagen, Meier, \& Elfering, 2007).

In contrast, given that task conflict typically is attributed to the situation (i.e., task) and not to the other person (Jehn, 1995), task conflict does not necessarily signal disrespect and rejection. Hence, task conflict is less likely to be a threat to the goals of belonging and to one's personal identity (e.g., De Dreu, Harinck, \& Van Vianen, 1999), as least as long as it is not linked to relationship conflict. However, relationship and task conflict often co-occur (e.g., De Dreu \& Weingart, 2003; Simons \& Peterson, 2000). For example, task conflict may be taken personally, transforming it into relationship conflict (see Glasl, 1982). Thus, task conflict may be associated with impaired well-being in part because it co-occurs with or precedes relationship conflict (e.g., Friedman et al., 2000). If negative associations of task conflicts with well-being are largely due to their association with relationship conflicts, the question arises about what effects "pure" task conflicts are likely to have. Based on the assumption that task conflict causes better performance (e.g., Jehn, 1995), some authors have argued for positive effects on well-being, as good performance and success may foster positive mood and self-esteem (Crocker \& Wolfe, 2001). Moreover, Deutsch (1973) proposed that conflict may prevent stagnation and stimulate interest and curiosity; thus, it cannot be ruled out that task conflict may be perceived as challenging and energizing (De Dreu, 2008).

However, there are good reasons to assume that task conflict may negatively affect well-being independent of relationship conflict. Task conflict implies negative feedback because one's opinion is considered to be wrong. Although such negative feedback may be communicated without personal animosities, it may threaten one's striving for a positive self-view (e.g., being competent) and may induce strain. In line with this, De Dreu and van Knippenberg (2005) showed in a set of laboratory studies that individuals tend to identify themselves with their ideas and make them part of their self. Of particular importance, opposition to these ideas and arguments are likely to be experienced as egothreatening and may trigger negative emotions. Therefore, it is likely that task conflict has negative effects on well-being independent of relationship conflict. However, these effects are likely to be smaller than those of relationship conflicts, as the latter have much broader implications for the social belonging of the focal person.

In sum, we hypothesized that both types of conflict are related to impaired well-being. However, given that only relationship conflict inherently threatens the basic need to belong and that positive effects, if they occur, are associated only with task conflict, we hypothesized that the effect on well-being would be stronger for relationship conflict compared with task conflict.

\section{Interaction of Relationship and Task Conflict: An Extended Attribution Analysis}

Previous research has not only largely neglected the independent effect of task conflict, it also has not taken into account that the effect of relationship conflict may depend on the level of task conflict. However, it has been proposed that the overall composition of the different types of conflict should be considered (e.g., Jehn \& Chatman, 2000). How could task conflict alter the association between relationship conflict and well-being? Our approach builds on the analysis by Jehn (1995) and Shaver (1985) in terms of attributions. In challenging events such as conflicts, people engage in an attribution process to explain the situation; depending on the attribution, different emotions are elicited (Lazarus, 1999; Weiner, 1985). Research on both conflict and revenge has shown that the more responsibility is attributed to the conflict partner (or harmdoer), the angrier the individual becomes (e.g., Allred, 2000; Bies \& Tripp, 1996; Betancourt \& Blair, 1992). In general, interpersonal tensions (relationship conflict) are attributed to the conflict partner, and disagreements about the content of a task (task conflict) are attributed to the situation (Jehn, 1995). Attributions to interaction partners suggest that relationship conflicts have stronger effects, and this is what the few existing studies that differentiated between task and relationship conflict have found. These studies, however, did not take into account that the presence or absence of a perceived task conflict may alter the perception of the relationship conflict. Based on the reasoning of Shaver (1985), full 
responsibility and blame for rude behavior will be assigned to a conflict partner when no other causes are apparent. However, responsibility and blame will be reduced if other causes are present. Therefore, when a conflict episode consists of both interpersonal animosities (relationship conflict) and disagreement about task-related problems (task conflict), negative aspects of the situation can, at least partly, be attributed to the task conflict. For instance, others' behavior that is perceived as impolite may be attributed to excitement resulting from the strong identification of the opponent with his or her viewpoint, implying that it likely does not reflect a general, and persistent, negative attitude toward the focal person but rather is likely to disappear once the situation is over. However, when a conflict episode is unrelated to task-related problems, the cause of the conflict can only be attributed to the conflict partner. When the attribution process points toward harmful intent of the conflict partner, people experience a stressful threat to self-esteem and social esteem (see Semmer et al., 2007).

Therefore, we hypothesized that relationship conflict would be more strongly related to impaired well-being when task conflict is low than when it is high. To the best of our knowledge, this interaction effect has been tested only by Guerra et al. (2005), who found the suggested pattern for job satisfaction but not for affective well-being. Thus, empirical testing is limited to a single cross-sectional study investigating chronic conflicts, and its findings are mixed.

\section{Short-Term Effects of Episodic Daily Conflict}

Most existing studies have assessed conflict in terms of enduring conditions. This type of assessment and the time lags chosen in longitudinal studies reflect a focus on how chronic stressors may affect well-being over an extended period of time. However, it is reasonable to assume that daily, not chronic, and maybe even isolated, conflicts have immediate effects. Even if these effects are short-lived, however, they are not trivial, because conflicttriggered emotions, such as anger, may start an incivility spiral or negatively affect the working climate (e.g., Andersson \& Pearson, 1999). Furthermore, their effect may spill over into the evening and impair recovery processes (e.g., Sonnentag, Kuttler, \& Fritz, 2010) and family members' well-being (e.g., Repetti, Wang, \& Saxbe, 2009). Thus, daily conflict and corresponding changes in well-being may play an important role in the development of chronic conditions.

Models of the effect of work conditions on well-being assume that stressors cause an acute reaction, which declines during a subsequent recovery phase under optimal circumstances (McEwen, 1998; Meijman \& Mulder, 1998). Thus, a crucial aspect of a successful recovery and decline of the effects is mental disengagement from work during leisure time (e.g., Etzion, Eden, \& Lapidot, 1998; Sonnentag, 2012). In line with this, previous research has indicated that a lack of psychological detachment and negative work reflections during leisure time are related to impaired well-being (e.g., Sonnentag \& Fritz, 2007). Moreover, several studies have shown that the negative effects of stressors on well-being are stronger at high (compared with low) levels of rumination; this effect holds on both a between-person level (e.g., work stressors are particularly strongly related to impaired well-being among people with low levels of detachment [i.e., high rumination]; e.g., Sonnentag, Unger, \& Nägel, in press) and a within-person level (daily negative events are particularly strongly related to negative mood on days when participants reported intense rumination use; e.g., Genet \& Siemer, 2012). In addition, experimental field studies have shown that a rumination instruction has a negative effect on mood (e.g., Huffziger, Ebner-Priemer, Koudela, Reinhard, \& Kuehner, 2012). In general, when people continuously think about the negative event, stress-related affective and physiological activations are prolonged, and the negative effects of work stressors last longer (see Brosschot, Gerin, \& Thayer, 2006). People are especially prone to ruminate about events that threaten fundamental goals, such as maintaining a positive self-view and a sense of belonging (see Martin \& Tesser, 1996). Conflicts therefore are likely to induce rumination, thus having prolonged effects. In line with this, a recent diary study showed that experiencing conflicts with customers is related to more negative work-related thoughts and impaired detachment (Volmer, Binnewies, Sonnentag, \& Niessen, 2012). Moreover, Dickerson and Kemeny (2004) found that negative social-evaluative situations such as conflicts are especially likely to induce persistent physiological activation. Therefore, it is reasonable to assume that conflict has immediate and prolonged effects on well-being.

Research is sparse on the duration of conflict effects. Experimental research has difficulties in faithfully modeling context factors, and it focuses on very short-lived effects, which is why Barry, Fulmer, and van Kleef (2004) called for more studies that use experience sampling methods in research on emotion in conflict. There are a few studies that have used such a methodology. Ilies et al. (2011) asked participants three times per day about prior conflicts in the prior $3 \mathrm{hr}$ at work and their current mood at work. With baseline mood controlled, conflicts were related to an immediate change as well as a lagged change of negative mood. The effects, however, were no longer apparent after $6 \mathrm{hr}$, suggesting that work conflict leads to an increase in negative mood during the same day. However, the study did not differentiate between task and relationship conflict, and it did not examine whether the effects may spill over into nonwork life and affect well-being during leisure time. Bolger, DeLongis, Kessler, and Schilling (1989) examined lagged effects of conflicts (at home or at work) on well-being the next day. Interestingly, they found a rebound effect; well-being was better after days with conflicts than after days without conflicts. Thus, research on the duration of the effect of conflict is rare, and more studies are needed before conclusions can be drawn. Knowledge about the potential prolongation of effects is especially important because it implies impaired recovery, and impaired recovery is likely a key component in the processes through which stressors may lead to long-term health impairments (Geurts \& Sonnentag, 2006; McEwen, 1998).

\section{Present Study}

In contrast to previous research that has focused on chronic relationship conflict, we investigated short-term effects of both daily relationship and task conflict on angry mood and somatic complaints in a daily diary study. The advantage of the daily diary approach is that it can more closely link events to well-being. Studies of chronic conflict and well-being are limited because they merely show that frequency of conflicts relates to a general level of well-being, but we cannot be certain that conflict is linked directly to well-being. It is possible that workplaces in which there 
is frequent conflict differ from those with little conflict in a variety of ways that might be linked to the well-being of employees. Even longitudinal studies of conflict are limited in conclusions because typically the timeframes chosen are arbitrary, making it impossible to ascertain whether well-being changed after exposure to conflict. Both designs are also vulnerable to the possibility that individual differences might confound the assessment of both conflict and well-being. The daily diary design allowed us to compare levels of well-being indicators from before to after conflict during the day within people, allowing us to link conflict to well-being indicators closely in time and to control for the possibility of individual differences with the within-person analyses. Thus, this design provides more confidence in conclusions that conflict is linked to well-being. Furthermore, a better understanding of the more proximal mechanisms may allow for more specific attempts at prevention and intervention.

In the present study, we focused on angry mood as an indicator of psychological well-being to ensure compatibility with the existing diary studies on work conflict (Hahn, 2000; Ilies et al., 2011). In addition, we focused on somatic complaints as an indicator of physical well-being to extend our knowledge about the independent effect of relationship and task conflict. As mentioned above, previous research has not tested the independent effect of task conflict on somatic complaints.

\section{Effects on Angry Mood}

Anger is a prominent reaction in conflict situations (e.g., Allred, 2000). According to Lazarus (e.g., 1991), anger arises when people experience a personal slight or a demeaning offense and hence a threat to their self-esteem. As noted above, both relationship and task conflict are likely to threaten one's self-esteem. Anger-or other emotions with a negative valence and high arousal, such as frustration-has been studied as a potential outcome of chronic work conflicts in cross-sectional research (e.g., Spector \& Jex, 1998) and as a short-term outcome of work conflict in diary studies (Hahn, 2000; Ilies et al., 2011). Moreover, both qualitative and experimental research about incivility (a stressor closely related to relationship conflict) have shown that the experience of rude behavior is linked to feelings of anger (e.g., Pearson, Andersson, \& Wegner, 2001; Porath \& Erez, 2007).

\section{Effects on Somatic Complaints}

Research has shown that stressors are detrimental not only to indicators of psychological well-being, such as mood, but also to somatic complaints (e.g., Frese, 1985; Spector \& Jex, 1998). Among others, the stress response is characterized by the activation of the sympathetic-adrenal medullar system, including increased heart rate, blood pressure, and catecholamine secretion. Over time, such reactions can result in the experience of somatic complaints, such as headache, back pain, and gastrointestinal problems. In line with this, conflict at work has been associated with increased somatic complaints in cross-sectional and longitudinal studies (Nixon, Mazzola, Bauer, Krueger, \& Spector, 2011). Most models attempting to explain how work conditions lead to physical symptoms focus on long timeframes and assume a chronification of the stressor as well as the physiological response. However, for this process to occur, there must be somatic reactions in the short term, which then become chronic over time. It therefore is reasonable to assume that daily stressors also cause somatic complaints in the short term. There is a body of research showing that daily fluctuations of work stressors are related to changes in physiology that cannot be directly experienced. For example, Ilies, Dimotakis, and de Pater (2010) showed that workload was positively related to blood pressure at work. Similarly, Kamarck et al. (2005) found a positive relationship between task demands and conflicts and blood pressure. Interestingly, however, only a few studies have tested whether daily fluctuations in work stressors are related to subjectively perceived somatic complaints. In a recent diary study by Bono, Glomb, Shen, Kim, and Koch (in press), the number of negative work events had no main effect on somatic complaints (but they had an effect when the number of positive work events was low). With regard to conflict at work, to our knowledge, there is only one study that showed short-term effects of conflict on subjectively perceived somatic symptoms (Hahn, 2000). There is, however, more research about the short-term effect of interpersonal tensions in general (i.e., not restricted to the work context) on somatic health. In a large-scale diary study, Almeida, Wethington, and Kessler (2002) found a positive relationship between interpersonal tensions and somatic complaints. However, a recent study could not replicate this effect (Hay \& Diehl, 2010). Therefore, the previous findings on the short-term effects of stressors on somatic complaints are inconclusive, and with regard to conflict at work, they are restricted to one study (Hahn, 2000), which did not differentiate between task and relationship conflict. Hence, further research on these topics is needed.

\section{Overview of the Current Study}

The present study extends previous research in several ways. First, this is the first study to use a longitudinal design to test the independent effects of relationship and task conflict on well-being. Furthermore, this is the first study to test the independent effect of task conflict on somatic complaints. Second, in contrast to previous research that largely neglected the interaction of relationship and task conflict, we also examined whether the effect of relationship conflict depends on the level of task conflict. Third, whereas most previous research focused on chronic conflict, the present study examined the duration of effects of daily conflict episodes on well-being using different time lags.

In sum, we postulated the following three hypotheses:

Hypothesis 1: Within individuals, there will be a positive effect of relationship and task conflict on angry mood and somatic complaints.

Hypothesis 2: Within individuals, the effects of relationship conflict on angry mood and somatic complaints will be stronger than the effects of task conflict.

Hypothesis 3: Within individuals, task conflict will moderate the effects of relationship conflict on angry mood and somatic complaints; specifically, the association of relationship conflict with angry mood and somatic complaints will be stronger when task conflict is low compared with high. 


\section{Method}

\section{Participants and Procedure}

The first and second authors asked their Swiss university students to recruit employees for the study. The students approached employees from several organizations, working in a variety of jobs (e.g., salesperson, commercial agent, secretary, consultant, controller, lawyer, nurse, physician, social worker, engineer, software developer) and asked them to participate in a diary study about organizational well-being. Participants had to work at least $50 \%$ of a full-time equivalent (about $21 \mathrm{hr} /$ week). During the study, the students regularly contacted the participants to sustain their participation. As compensation for the participants' time, we offered them individual feedback about their work situation and wellbeing at the end of the study.

The sample consisted of 131 employees. Their ages ranged from 16 to 62 years $(M=33.4$ years, $S D=12.6)$. The majority of participants were women $(64 \%) ; 13 \%$ had completed regular school (9 years) or an apprenticeship, $61 \%$ had completed college, and $26 \%$ had a university degree. On average, they worked 36.1 $\mathrm{hr} /$ week $(S D=7.1)$ and organizational tenure ranged from 0.1 to 30 years $(M=3.2$ years, $S D=5.9)$. Twenty-six percent of the participants held a supervisory position.

Participants first completed a one-time questionnaire to assess demographic variables. At the beginning of the following week, participants began completing several paper-and-pencil surveys per day for 2 weeks (including weekends) using a fixed time-based sampling strategy. On a working day, participants filled in a morning survey (before they started working), an end-of-work survey, and a bedtime survey. On a nonworking day, participants filled in only a morning and a bedtime survey. Of the 131 participants, 29 did not report any working day with conflicts. Thus, 29 participants had no intraindividual variance in the conflict measure. Although authors of prior studies eliminated participants who did not report any of the target experiences (e.g., Ilies et al., 2011; Meier, Semmer, \& Hupfeld, 2009), we retained all 131 participants, as we also examined between-person effects of conflict (see below). Overall, participants completed 1,811 morning surveys, 1,092 end-of-work surveys, and 1,791 bedtime surveys, corresponding to a response rate of $99 \%$ for the morning surveys and $98 \%$ for the bedtime surveys. Because the end-of-work survey had to be taken only on workdays and not all participants worked full time, calculating an accurate response rate for the end-of-work survey was not possible. However, participants had to indicate whether it was a workday in the morning survey and, on the basis of this information, the response rate for the end-of-work survey was $95 \%$. Furthermore, participants indicated whether a survey had been filled out with a delay of more than 15 min from the prescribed time point. For the subsequent analyses, we used only the surveys that had been filled out on time (1,707 morning surveys, 988 end-of-work surveys, and 1,683 bedtime surveys, corresponding to an average of $13.0[S D=1.6]$ morning surveys, $7.5[S D=2.3]$ end-of-work surveys, and $12.8[S D=1.7]$ bedtime surveys).

To test deterioration of compliance over time, we examined whether day of study (ranging from 1 to 14) was related to missing data $(0=$ no missing data, $1=$ missing data $)$. For the morning and the bedtime survey, day of study was unrelated to missing data.
For the end-of-work survey, day of study was negatively related to missing data $(r=-.06, p<.05)$, indicating that compliance did not deteriorate over time; rather, it slightly increased on a general high level. Additional analyses indicated that participants' level of noncompliance (i.e., number of missing data points) was unrelated to the average level of the daily measures as well as to demographic variables (age, gender, education, organizational tenure, average working hours, and supervisory function).

\section{Measures}

Relationship and task conflict at work. At the end of work, relationship and task conflict were assessed with a shortened (three items each) and adapted version of the scale by Jehn (1995; Shah \& Jehn, 1993). We reworded the instructions and the items to refer to what participants experienced during a working day. Relationship conflict was assessed with the following three items: "Today, frictions existed among members of the team and me"; "Today, tensions existed among members of the team and me"; and "Today, emotional conflicts existed between members of the team and me." Task conflict was assessed with the following three items: "Today, the team and I disagreed about the way to complete a team task"; "Today, the team and I disagreed about who should do what"; and "Today, the team and I disagreed about a decision." The response format ranged from 1 (completely disagree) to 5 (completely agree). ${ }^{1}$

Angry mood. At all three measurement occasions per day, angry mood was assessed with a shortened version of the Profile of Mood States (McNair, Lorr, \& Droppleman, 1992). Following Cranford et al. (2006), we used three items (angry, resentful, annoyed). Participants had to indicate how they felt at the moment. The response format ranged from 1 (not at all) to 5 (very much).

Somatic complaints. At all three measurement occasions per day, somatic complaints were assessed with six questions based on a measure by Mohr (1986; cf. Frese, 1985). Headache, gastrointestinal problems, and back pain are typical somatic complaints assessed in occupational health research (e.g., Spector \& Jex, 1998); these were measured with two items each. Participants had to indicate how they felt at the moment. The response format ranged from 1 (completely disagree) to 5 (completely agree).

\section{Results}

Because the daily data were nested within persons, we analyzed them with a multilevel random coefficient model (Nezlek, 2011), using the program HLM 6.06 (Raudenbush, Bryk, Cheong, \& Congdon, 2004). The main focus of the analyses was on within-

\footnotetext{
${ }^{1}$ To examine whether relationship conflict and task conflict are distinct constructs, we conducted a multilevel confirmatory factor analysis using the program Mplus 6 (Muthén \& Muthén, 2010), taking into account that the daily data are nested within persons. Results supported that the two subscales reflected different constructs in that a one-factor model did not fit well, $\chi^{2}(23)=232.81$, comparative fit index $(\mathrm{CFI})=0.71$, Tucker-Lewis index $(\mathrm{TLI})=0.63$, root mean square error of approximation $(\mathrm{RMSEA})=$ 0.09 , standardized root mean residual $\left(\mathrm{SRMR}_{\text {between }}\right)=0.11, \mathrm{SRMR}_{\text {within }}=$ 0.24 , but a two-factor model did, $\chi^{2}(22)=53.38$, CFI $=0.95$, TLI $=0.94$, RMSEA $=0.04, \mathrm{SRMR}_{\text {between }}=0.04, \mathrm{SRMR}_{\text {within }}=0.11$. The subscales were related $\left(r_{\text {within }}=.52, r_{\text {between }}=.64\right.$; see Table 1$)$, which is in line with the meta-analytic finding of $\rho=.54$ by De Dreu and Weingart (2003).
} 
person relationships of conflict at work with angry mood and somatic complaints. To model change in the outcome, we controlled for its preceding level (e.g., angry mood in the morning). These predictors were group mean-centered, implying that the coefficients for these variables reflect the effect of a person being high or low (e.g., many or few conflicts) relative to his or her own mean for that variable across days. Thus, between-person variance in these variables was removed, and an interpretation of the results in terms of stable differences between persons can be ruled out (cf. Ilies, Schwind, \& Heller, 2007). Average levels of conflict, however, are neglected by group mean-centering. Therefore, to examine the effect of the average level of conflicts on well-being, we additionally used the aggregated daily measures of conflict as between-person variables, which were grand mean-centered. Instead of conducting separate analyses for each time lag (i.e., separate analyses for the four measurement occasions, namely end of work, bedtime, next morning, end of work the next day), we conducted multilevel analyses described by Nezlek (2007). For each outcome, we conducted three-level models in which items were nested within days, which were nested within people. Thus, Level 1 represents a measurement model, Level 2 represents within-person effects (the focus of the present study), and Level 3 represents between-person effects. We used the restricted maximum-likelihood procedure in HLM for estimating the fixed and random parameters, and because of the nonnormal distribution of the outcome variables, we used the robust standard errors for the significance tests (see Hox, 2010).

\section{Main Analyses}

Means, standard deviations, intraclass correlations, and zeroorder correlations for the daily measures are shown in Table 1. Relationship and task conflict were strongly related to one another; both types of conflict were related to angry mood, but not to somatic complaints. Table 2 presents the multilevel analyses. Within person, relationship conflict was positively related to angry mood at the end of work and at bedtime, but not to angry mood the following day. In contrast, task conflict was unrelated to angry mood at all measurement points. With regard to somatic complaints, neither relationship conflict nor task conflict was predictive at any measurement point. $^{2}$ Concerning between-person effects, only aggregated relationship conflict was positively related to angry mood, and neither type of conflict was related to somatic complaints.

To directly test whether relationship conflict was more strongly related to well-being than task conflict, we compared the unconstrained model with a constrained model, in which the slopes of relationship conflict were set to be equal to the slopes of task conflict (detailed information can be obtained from the first author). Regarding within-person effects, the constrained model for angry mood as outcome differed significantly from the unconstrained model; thus, the effect of relationship conflict on anger was stronger than the effect of task conflict. Additional analyses for each measurement occasion separately indicated that the effects differed from each other at the end of work and at bedtime, but not the next day. For somatic complaints as the outcome, the effects did not differ from each other. Regarding between-person effects, overall, the effects of relationship conflict on anger were stronger than the effects of task conflict; for somatic complaints, however, the effects did not differ from each other.

Finally, in line with our assumption, four interactions between daily fluctuations of relationship and task conflict were significant. To examine the interactions in more detail, we conducted simple slope tests. Because there exists no tool for simple slope tests for our three-level multivariate model, we conducted additional twolevel analyses to use the tool of Preacher, Curran, and Bauer (2006). Simple slope tests (see Table 3) showed that relationship conflict was related to angry mood at bedtime and the next morning when task conflict was low, but not when task conflict was high. With regard to somatic complaints, relationship conflict was related to somatic complaints the next morning when task conflict was low, but not when task conflict was high. A similar result was found for somatic complaints at the end of work the following day; however, both simple slopes did not reach statistical significance. The pattern is presented using procedures recommended by Aiken and West (1991) in Figure 1.

\section{Additional Analyses: Spurious Effects Because of Negative Affectivity?}

There is an ongoing debate about the role of negative affectivity (NA) in stress research, with some noting that NA differences affect the experience and/or measurement of stressors and wellbeing, leading to a biased estimate of their association (e.g., Watson, Pennebaker, \& Folger, 1987). As we group meancentered our day-specific predictors, all interindividual variance in these predictors had been removed and the within-person effects cannot be explained by interindividual differences in NA or other personality variables (e.g., Ilies et al., 2007). However, the (between-person) effects of the average level of conflict could be affected by the participants' level of NA. We therefore ran additional analyses with chronic NA as a person-level covariate. NA was measured with an abbreviated nine-item version of the Profile of Mood States (McNair et al., 1992) before the 2-week diary period started. Including NA altered neither within-person effects nor between-person effects of conflict on angry mood and somatic complaints; therefore, the findings reported above cannot be explained by interindividual differences in NA. Detailed information on the additional analyses can be obtained from the first author.

\section{Discussion}

We investigated the effects of conflict at work on angry mood and somatic complaints in a diary study, and we focused on intraindividual changes in a comparatively short timeframe, ranging from end of work until the following day. Extending previous research by differentiating between relationship and task conflict, we tested both independent and interactive effects of relationship and task conflict. Overall, our results indicated that task conflict

\footnotetext{
${ }^{2}$ A recent meta-analysis found that some physical symptoms (e.g., gastrointestinal problems) were more strongly related to work conditions than others (Nixon et al., 2011). We therefore ran additional analyses for each symptom (i.e., gastrointestinal problems, headache, back pain) to test whether conflicts were related to only some but not other symptoms. However, the results mirror those of the overall score, as both types of conflict were unrelated to the three types of symptoms.
} 
Table 1

Sample Sizes, Means, Standard Deviations, and Correlations of the Daily Measures

\begin{tabular}{|c|c|c|c|c|c|c|c|c|c|c|c|c|c|}
\hline Variable & $n$ & $M$ & $S D_{\mathrm{b}-\mathrm{p}}$ & $S D_{\mathrm{w}-\mathrm{p}}$ & ICC & 1 & 2 & $3 a$ & $3 b$ & $3 \mathrm{c}$ & $4 a$ & $4 b$ & $4 \mathrm{c}$ \\
\hline 1. Relationship conflict & 968 & 1.25 & 0.24 & 0.54 & .16 & $(.82)$ & $.64^{*}$ & $.34^{*}$ & $.50^{*}$ & .16 & .12 & .11 & .10 \\
\hline 2. Task conflict & 958 & 1.21 & 0.23 & 0.44 & .21 & $.52^{*}$ & (.68) & $.34^{*}$ & $.39^{*}$ & $.20^{*}$ & .08 & .04 & .04 \\
\hline \multicolumn{14}{|l|}{ 3. Anger } \\
\hline a. Morning & 1,702 & 1.07 & 0.10 & 0.28 & .10 & .10 & .08 & $(.83)$ & $.52^{*}$ & $.60^{*}$ & $.37^{*}$ & $.32^{*}$ & $.41^{*}$ \\
\hline b. End of work & 987 & 1.14 & 0.12 & 0.41 & .08 & $.40^{*}$ & $.23^{*}$ & $.13^{*}$ & $(.88)$ & $.51^{*}$ & .11 & .10 & .13 \\
\hline c. Bedtime & 1,682 & 1.10 & 0.12 & 0.27 & .11 & $.16^{*}$ & $.17^{*}$ & $.20^{*}$ & $.30^{*}$ & (.89) & $.24^{*}$ & .16 & $.24 *$ \\
\hline \multicolumn{14}{|l|}{ 4. Somatic complaints } \\
\hline a. Morning & 1,697 & 1.23 & 0.25 & 0.30 & .40 & .04 & .03 & $.18^{*}$ & .02 & .02 & $-^{a}$ & $.80^{*}$ & $.84^{*}$ \\
\hline b. End of work & 985 & 1.26 & 0.28 & 0.28 & .49 & .03 & .01 & $.11^{*}$ & .06 & .04 & $.62^{*}$ & $-^{a}$ & $.86^{*}$ \\
\hline c. Bedtime & 1,680 & 1.23 & 0.26 & 0.28 & .45 & .01 & -.01 & $.15^{*}$ & .03 & $.09^{*}$ & $.52^{*}$ & $.68^{*}$ & $-^{a}$ \\
\hline
\end{tabular}

Notes. $S D_{\mathrm{b}-\mathrm{p}}=$ between-person standard deviation; $S D_{\mathrm{w}-\mathrm{p}}=$ within-person standard deviation; ICC $=$ intraclass correlation (proportion of the between-person variance compared with the total variance). Standard deviations and ICCs are based on variance estimates of unconditional (null) models (see Nezlek, 2011). Correlations below the diagonal reflect the within-person associations of the constructs of the same day and were calculated with Mplus (Muthén \& Muthén, 2010). Correlations above the diagonal reflect the between-person associations of the aggregated daily measures. Reliability estimates were calculated according to Nezlek (2011) and are shown within parentheses on the diagonal of the table.

${ }^{\text {a }}$ The sum of these items is a meaningful indicator of somatic complaints; however, they do not reflect a single underlying construct. Therefore, internal consistency is not a meaningful measure for this scale (see Spector \& Jex, 1998).

$* p<.05$.

was bivariately related to angry mood, but not to somatic complaints, and was unrelated to both outcomes when relationship conflict was controlled. In contrast, relationship conflict was positively related to angry mood, but not to somatic complaints at the daily level, even when task conflict was controlled. Moreover, our findings indicate that relationship conflict was related to wellbeing more strongly when task conflict was low than when it was high. In other words, relationship conflict is associated with more anger when it occurs alone than when it is accompanied by task conflict. Thus, the effect of relationship conflict varies with context.

\section{Relationship Conflict}

The fact that relationship conflict was negatively related to negative mood is in line with previous research. That research, however, was mainly limited to chronic work conditions and based on cross-sectional data. As an exception, Ilies et al. (2011) showed that conflict had lagged short-term effects on negative mood at work; however, Ilies et al. referred to conflict in general and did not distinguish between relationship and task conflict; furthermore, they only focused on mood at work. Our study further shows that relationship conflict not only had an effect on mood at work, but also spilled over into the evening; hence, it is likely to impair the unwinding process (Geurts \& Sonnentag, 2006). Moreover, as conflict is linked to angry mood in the evening, third persons such as spouses may also be affected by work conflicts (see Repetti et al., 2009).

\section{Interaction of Relationship and Task Conflict}

The present study is one of the first to follow the suggestion of Jehn and Chatman (2000) to consider the overall composition of conflicts, and we examined whether the effect of relationship conflict depends on the level of task conflict. In line with the results of Guerra et al. (2005), relationship conflict was related to well-being only when task conflict was low but not when it was high. We had hypothesized this interaction, based on attribution theory considerations. When relationship conflict arises from task conflict, likely an individual will attribute the relationship conflict externally to the task situation rather than internally to the conflict partner. In other words, the partner might be given the benefit of the doubt in becoming angry and saying something unkind. When there is no task conflict, likely the attribution for the relationship conflict is internal to the conflict partner, thus inducing more anger.

Interestingly, task conflict had a moderating effect for angry mood only at bedtime and the next morning, but not for the rather immediate effect at the end of the workday. Although we did not hypothesize this pattern, it is in line with our assumption that attribution and ruminative thoughts play an important role in the origin and prolongation of stress reactions. Conflict is likely to arouse immediate anger. After work, however, people are prone to think about their conflicts and discuss them with other people (e.g., spouse; see Amstad \& Semmer, 2009; Brosschot et al., 2006). By thinking about the conflict episode, people may reappraise the conflict episode and, in doing so, may separate aspects related to the task versus the relationship more clearly (e.g., "Did he or she attack me personally because we disagreed about a task-related topic?"). Thus, attribution and the effect of relationship and task conflict may change in the course of time (e.g., at work vs. later at home). In terms of the emotions as social information model (Van Kleef, 2009), it seems likely that the process starts with a dominance of the affective reaction and rather shallow information processing, and then gives way to more thorough information processing, leading to a dominance of cognitive inferences over the immediate affective reaction.

Future research, however, should try to replicate our finding and examine the suggested mediating mechanism of attributions and the role of rumination more explicitly. Our reasoning on the prolonged effects of conflict is based on the assumption that lack of psychological detachment and negative work-related thoughts impair the recovery process and sustain stress-related affective and physiological activation. Therefore, ruminating about work prob- 
Table 2

Multilevel Analyses Predicting Angry Mood and Somatic Complaints From Relationship and Task Conflict

\begin{tabular}{|c|c|c|c|c|c|c|}
\hline \multirow[b]{2}{*}{ Measure } & \multicolumn{3}{|c|}{ Angry mood } & \multicolumn{3}{|c|}{ Somatic complaints } \\
\hline & $B$ & $\beta$ & $S E B$ & $B$ & $\beta$ & $S E B$ \\
\hline \multicolumn{7}{|c|}{ DV measured at end of work } \\
\hline Intercept & $1.13^{* *}$ & - & 0.01 & $1.27^{* *}$ & - & 0.03 \\
\hline \multicolumn{7}{|c|}{ Between-person effects } \\
\hline $\mathrm{RC}$ & $0.28^{* *}$ & $.16^{* *}$ & 0.06 & 0.11 & .09 & 0.10 \\
\hline $\mathrm{TC}$ & -0.06 & -.03 & 0.06 & $<0.01$ & $<.01$ & 0.12 \\
\hline \multicolumn{7}{|c|}{ Within-person effects } \\
\hline DV at morning & 0.04 & .03 & 0.05 & $0.26^{* * *}$ & $.28^{* * *}$ & 0.06 \\
\hline $\mathrm{RC}$ & $0.22^{* *}$ & $.29^{* * *}$ & 0.05 & 0.03 & .06 & 0.03 \\
\hline $\mathrm{TC}$ & -0.05 & -.05 & 0.03 & -0.01 & -.02 & 0.02 \\
\hline $\mathrm{RC} \times \mathrm{TC}$ & -0.09 & -.09 & 0.11 & -0.02 & -.03 & 0.03 \\
\hline \multicolumn{7}{|c|}{ DV measured at bedtime } \\
\hline Intercept & $1.12^{* * *}$ & - & 0.02 & $1.23^{* *}$ & - & 0.02 \\
\hline \multicolumn{7}{|c|}{ Between-person effects } \\
\hline $\mathrm{RC}$ & 0.06 & .05 & 0.07 & 0.13 & .12 & 0.09 \\
\hline $\mathrm{TC}$ & 0.13 & .11 & 0.09 & -0.05 & -.04 & 0.09 \\
\hline \multicolumn{7}{|c|}{ Within-person effects } \\
\hline DV at morning & 0.10 & .10 & 0.07 & $0.14^{* *}$ & $.16^{* *}$ & 0.04 \\
\hline $\mathrm{RC}$ & $0.12^{* *}$ & $.24^{* *}$ & 0.04 & -0.03 & -.06 & 0.01 \\
\hline $\mathrm{TC}$ & -0.01 & -.02 & 0.05 & -0.01 & -.02 & 0.02 \\
\hline $\mathrm{RC} \times \mathrm{TC}$ & $-0.24^{* *}$ & $-.35^{* * *}$ & 0.07 & $<0.01$ & $<.01$ & 0.02 \\
\hline \multicolumn{7}{|c|}{ DV measured the next morning } \\
\hline Intercept & $1.08^{* * *}$ & - & 0.01 & $1.22^{* *}$ & - & 0.02 \\
\hline \multicolumn{7}{|c|}{ Between-person effects } \\
\hline $\mathrm{RC}$ & $0.15^{*}$ & $.13^{*}$ & 0.07 & 0.10 & .08 & 0.08 \\
\hline $\mathrm{TC}$ & 0.06 & .05 & 0.07 & 0.02 & .02 & 0.09 \\
\hline \multicolumn{7}{|c|}{ Within-person effects } \\
\hline DV at morning & -0.04 & -.04 & 0.04 & 0.09 & .09 & 0.06 \\
\hline $\mathrm{RC}$ & 0.05 & .10 & 0.03 & 0.03 & .05 & 0.02 \\
\hline $\mathrm{TC}$ & 0.03 & .05 & 0.04 & -0.02 & -.03 & 0.03 \\
\hline $\mathrm{RC} \times \mathrm{TC}$ & $-0.18^{*}$ & $-.25^{*}$ & 0.07 & $-0.07^{*}$ & $-.09^{*}$ & 0.03 \\
\hline \multicolumn{7}{|c|}{ DV measured at the end of work at next day } \\
\hline Intercept & $1.14^{* * *}$ & - & 0.02 & $1.27^{* *}$ & - & 0.03 \\
\hline \multicolumn{7}{|c|}{ Between-person effects } \\
\hline $\mathrm{RC}$ & $0.36^{* * *}$ & $.21^{* * *}$ & 0.08 & 0.15 & .13 & 0.10 \\
\hline $\mathrm{TC}$ & -0.17 & -.10 & 0.09 & -0.03 & -.02 & 0.12 \\
\hline \multicolumn{7}{|c|}{ Within-person effects } \\
\hline DV at morning & -0.07 & -.05 & 0.09 & -0.05 & -.05 & 0.05 \\
\hline $\mathrm{RC}$ & -0.07 & -.09 & 0.06 & 0.02 & .04 & 0.04 \\
\hline $\mathrm{TC}$ & -0.02 & -.02 & 0.07 & -0.04 & -.06 & 0.04 \\
\hline $\mathrm{RC} \times \mathrm{TC}$ & -0.16 & -.15 & 0.12 & $-0.08^{* * *}$ & $-.11^{* *}$ & 0.03 \\
\hline
\end{tabular}

Note. $\quad \mathrm{RC}=$ relationship conflict; $\mathrm{TC}=$ task conflict; $\mathrm{DV}=$ dependent variable. Standardized coefficients $(\beta)$ were calculated using the formula $\beta=$ $B \times S D x / S D y$ (see Hox, 2010).

${ }^{*} p<.05 .{ }^{* * *} p<.01$.

lems (e.g., conflicts) and its consequences (e.g., negative affect) are assumed to have detrimental effects on employees' well-being.

However, it seems likely that there are different types of ruminative thoughts, which may have different effects on well-being. Cropley and Zijlstra (2011) differentiated between affective rumination (as a cognitive state characterized by the appearance of intrusive and recurrent negative work-related thoughts) and problem-solving pondering (as prolonged mental scrutiny of problem to see how it can be solved without the emotional process that sustains the affective and physiological arousal). A recent crosssectional study showed that only affective rumination was negatively related to well-being; in contrast, problem-solving pondering was positively related to well-being (Querstret \& Cropley, 2012). Related to this, Treynor, Gonzalez, and Nolen-Hoeksema (2003) showed that brooding (i.e., passive comparison of one's situation with unachieved goals) was positively related to depressive symptoms both concurrently and in the long run, whereas reflection (i.e., cognitive problem solving, conceptually similar to the problem-solving pondering of Cropley \& Zijlstra, 2011) was positively related to depressive symptoms concurrently, but was associated with less depressive symptoms over time. Thus, although problem-solving-oriented pondering may be emotionally stressful in the short run, it may be adaptive in the long run, as it may take time to sort things out.

Additional evidence that the type of thoughts affects the duration of the negative effects comes from experimental research (Ray, Wilhelm, \& Gross, 2008): Participants who ruminated about a negative event from their own perspective experienced more anger, more cognitive perseveration, and greater sympathetic nervous system activation than participants who were instructed to 
Table 3

Effects of Relationship Conflict on Angry Mood and Somatic Complaints Depending on the Level of Task Conflict

\begin{tabular}{lcc}
\hline \multicolumn{1}{c}{ Outcome } & Low task conflict & High task conflict \\
\hline Angry mood & & \\
$\quad$ Bedtime & $0.17(.34)^{* * *}$ & $0.02(.04)$ \\
$\quad$ Next morning & $0.12(.23)^{* * *}$ & $0.01(.02)$ \\
Somatic complaints & $0.06(.12)^{*}$ & $-0.01(-.02)$ \\
$\quad$ Next morning & $0.04(.08)$ & $<0.01(<.01)$ \\
$\quad$ End of work next day &
\end{tabular}

Note. Unstandardized and standardized (within parentheses) coefficients are reported.

${ }^{*} p<.05$. ${ }^{* *} p<.01$.

think about the event from a different perspective (e.g., another party involved). Therefore, it is possible that, on the one hand, ruminating about an experienced conflict is likely to sustain negative emotions and hence increases the duration of the effect; on the other hand, thinking about the conflict in a problem-solving way could be instrumental in the long run as it may help the person handle this or future conflicts by increasing perspective taking, which is related to successful conflict management (e.g., Galinsky, Maddux, Gilin, \& White, 2008). Future research should therefore examine the type of work-related thoughts in detail.

\section{Task Conflict}

The present study indicates that it is important to differentiate between relationship and task conflict. In contrast to our assump- tion, but in line with previous results from cross-sectional studies (Giebels \& Janssen, 2005; Guerra et al., 2005), task conflict was not related to angry mood once relationship conflict was controlled. We reasoned that task conflict may have detrimental effects on well-being independent of its association with relationship conflict because it threatens one's striving for a positive self-view. We still maintain that task conflict can threaten the self in this way. However, one has to consider several other aspects of the conflict situations that may counter this threat. For example, a disagreement may be limited to parts of the discussion, or it may even end with the conflict partners agreeing with one's point of view, making a person feel competent and boosting his or her selfesteem. A disagreement may also result in new insights, creative solutions, and more efficient problem solving, which may have positive effects (see Jehn, 1995). Finally, task conflict may well occur in an atmosphere of respect and appreciation (cf. Baron, 1988), thereby fostering an atmosphere of psychological safety (see Edmondson, 1999). To the extent that disagreements have these qualities, they need not result in negative reactions of the kind we investigated (see De Dreu, 2008). The role of social support in attenuating effects of conflict found by Guerra et al. (2005) and Ilies et al. (2011) are in line with these assumptions.

\section{Somatic Complaints}

Previous research about short-term effects of work stressors on physical well-being have mainly focused on physiological reactions (e.g., blood pressure; e.g., Ilies et al., 2010), but little is known about whether stressors also affect subjectively perceived somatic complaints in the short run. Addressing this, we examined
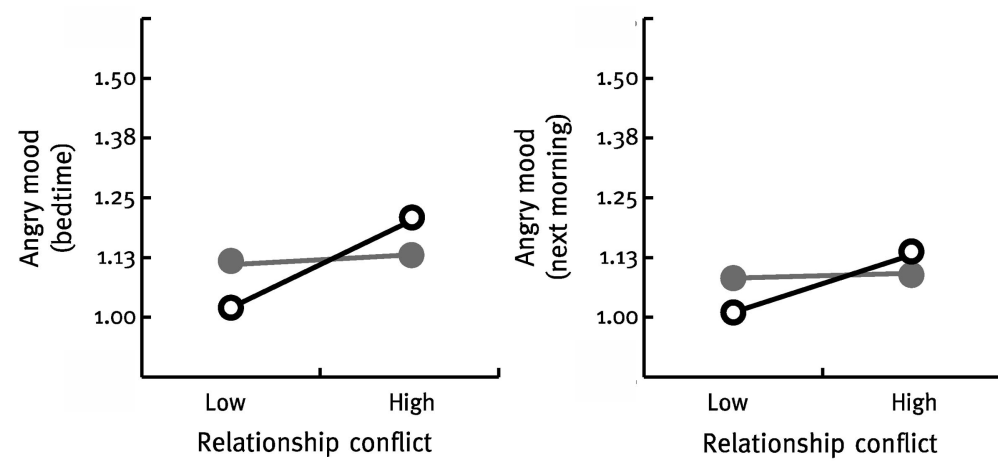

High task conflict

Relationship conflict

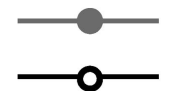

Low task conflict
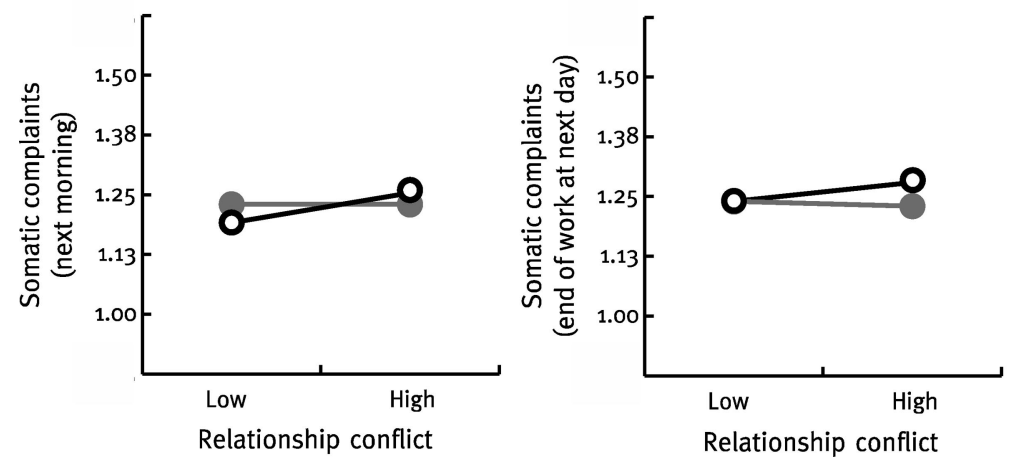

Figure 1. Interactions between daily relationship and task conflicts predicting well-being. 
whether daily conflict was related to short-term changes in headache, back pain, and gastrointestinal problems. Contrary to our assumption, conflict was unrelated to subjectively perceived somatic complaints. This stands in contrast to the diary study by Hahn (2000). It should be noted, however, that Hahn used a broader measure of conflict that also included interferences between work and family life, as well as a broader measure of somatic complaints. Furthermore, she did not control for baseline level in the analyses; hence, the results of the two studies should be compared with caution. Our results also stand in contrast to cross-sectional research about chronic work conflict (e.g., Spector \& Jex, 1998). To affect somatic complaints, conflicts presumably have to fulfill one of two conditions. First, they have to occur more frequently or occur over an extended period of time, thus representing chronic interpersonal tensions. These considerations point to the importance of differentiating between short-term and longterm effects, and they highlight that relatively little is known about the time course of the effects that stressors have on health and well-being (Mitchell \& James, 2001). Second, somatic complaints may result from conflict incidents only if the intensity of the incident is high. Future studies should therefore measure associations between conflict and somatic complaints with various time lags (e.g., day, week, month) to better distinguish short-term and long-term effects, and they should sample more conflict episodes and get a measure of their intensity.

\section{Limitations}

Certain limitations in the present study should be acknowledged. First, although memory biases are generally reduced with daily measures compared with one-time global assessments, the interpretation of episodic conflicts may alter within short time spans (e.g., hours); hence, assessing conflict only once per day is an important limitation. Depending on the sampling procedure, different types of processes are being measured. Conner and Feldman Barrett (2012) discussed these processes in terms of different selves, namely the experiencing (momentary), remembering (retrospective), and believing (trait) self. Using an event-sampling procedure in which participants are requested to report a conflict episode immediately after it happened (for an example, see JensenCampbell \& Graziano, 2000) best captures the experiencing self. Of particular interest, Conner and Feldman Barrett noted that it is the experiencing self that is most strongly related to bodily reactions such as cardiovascular and hypothalamic-pituitary-adrenal axis reactivity. Therefore, future studies should use an eventsampling approach to measure conflict as well as mood and somatic symptoms as they occur. Moreover, other physiological stress responses that cannot be directly perceived but may be triggered by acute stress, such as high blood pressure, could also be examined.

Second, and related to the previous point, future studies should also focus on a broader variety of somatic complaints. In the present research, we assessed only headache, gastrointestinal problems, and back pain; hence, it is unknown whether daily fluctuations of conflict are related to short-term fluctuations of other symptoms, such as musculoskeletal pain. However, it is important to note that chronic conflict has been linked to headache, gastrointestinal problems, and back pain in previous cross-sectional research (see Nixon et al., 2011), suggesting that our conclusion that different mechanisms come into play in short-and long-term effects of work stressors on somatic complaints is not unwarranted.

Third, the present study did not test the mediating mechanisms of ruminative thoughts and attributions; rather, we inferred such processes based on appraisal theories of emotion. Therefore, future studies should test a model in which rumination (negative), problem-solving pondering (positive), and attributions-predicted by the interplay of the two types of conflicts-mediate the negative effect of conflict on well-being.

Fourth, the present study suggested that conflict is prospectively linked to impaired well-being. However, it may be that the relationship between conflict and well-being merely reflects the effect of a third variable. For example, it cannot be ruled out that other stressors such as workload caused conflict and, independently, also caused impaired well-being.

Fifth, the study was based on a convenience sample, which imposes limits on generalizability. More specifically, our sample was rather highly educated, which may imply lower reactivity to stressors in general and to conflict in particular (cf. Almeida, 2005). It is noteworthy that participants in our study experienced relatively few conflicts and had a rather high level of well-being. Interestingly, even fluctuations at such low levels (and hence with restricted variance) yielded significant associations between wellbeing and conflict. Nevertheless, it is possible that some effects emerge only with high levels of conflict. Future research should therefore examine effects of conflict on well-being among people with more frequent and more severe conflicts.

\section{Conclusions and Practical Implications}

Our findings have implications for the management of conflict in organizations. With regard to relationship conflict, our results confirm the general finding that relationship conflict has negative consequences. Thus, it is important for managers to create climates of trust in which employees can feel free to disagree without that disagreement escalating into relationship conflict. This can be accomplished by managers modeling the sorts of responses to disagreements that will avoid relationship conflict, and by taking corrective actions when individuals respond to respectful disagreement with relationship conflict.

With regard to task conflict, our results suggest that the detrimental relationship of task conflict with well-being is likely due to the co-occurrence of both forms of conflict. Thus, our results do not support our hypothesis that task conflict itself is detrimental for well-being. On the other hand, we could not find positive effects of task conflict, even after the variance shared with relationship conflict was controlled. Therefore, our results do not support the claim that task conflict in general is likely to be beneficial, at least with regard to well-being (Pondy, 1992). One possible conclusion is that task conflict may be a double-edged sword, containing (a) potentially positive aspects that lead to insights and to better problem solving, and through the experience of these effects to pride and increased self-esteem, and (b) the negative aspects mentioned (i.e., seeing one's viewpoint attacked). The two aspects may well cancel each other out, leading to a null effect if task conflict is treated as a unitary construct (after partialing out the effects of relationship conflict). Therefore, neither the advice to induce, or even reinforce, task conflict nor the advice to avoid task conflict seems warranted at this point. 
However, once people disagree, it does seem advisable to carefully word one's disagreements in terms of the issue at hand, that is, task-related, and to avoid "people-oriented" attacks (Steinel et al., 2008). If relationship conflict occurs, it may be beneficial to support attributions in terms of task aspects. In this respect, the implications of our study go beyond those of most other studies: Not only avoiding statements that imply people-oriented attacks is useful, once these have occurred, but it also may be helpful to support a reappraisal of these statements in terms of task-related disagreement (e.g., "He only said that because he wanted to defend his position"). Such attempts at reappraisal may well take place after the conflict episode is over, supporting the idea of a conflict debriefing. In fact, to the extent that our discussion of immediate affective dominance giving way to more differentiated cognitive processing later on is correct, this would even suggest that such a debriefing may be most useful when some time has passed.

In sum, our results extend previous research about short-term effects of work conflict on well-being. Showing that task conflict is unrelated to well-being once relationship conflict is controlled implies that task conflict cannot be advocated as a useful practice in general. Showing that task conflict may mitigate the effects of relationship conflict, however, our results suggest that once conflict does arise, effort should be made to appraise in terms of task conflict as much as possible. At the same time, our research stimulates a number of questions, which refer to issues of timeframes and intensity, and to the specific aspects contained in task conflict that may be beneficial (i.e., fostering good decisions) or detrimental (i.e., arousing defensiveness and fostering relationship conflict).

\section{References}

Aiken, L. S., \& West, S. G. (1991). Multiple regression: Testing and interpreting interactions. Newbury Park, CA: Sage.

Allred, K. G. (2000). Anger and retaliation in conflict: The role of attribution. In M. Deutsch \& P. T. Coleman (Eds.), The handbook of conflict resolution: Theory and practice (pp. 236-255). San Francisco, CA: Jossey-Bass.

Almeida, D. (2005). Resilience and vulnerability to daily stressors assessed via diary methods. Current Directions in Psychological Science, 14, 64-68. doi:10.1111/j.0963-7214.2005.00336.x

Almeida, D. M., Wethington, E., \& Kessler, R. C. (2002). The daily inventory of stressful events an interview-based approach for measuring daily stressors. Assessment, 9, 41-55.

Amstad, F. T., \& Semmer, N. K. (2009). Recovery and the work-family interface. In P. L. Perrewé, D. C. Ganster, \& S. Sonnentag (Eds.), Research in occupational stress and well-being: Vol. 7. Current perspectives on job-stress recovery (pp. 125-166). Bingley, UK: Emerald Group.

Andersson, L., \& Pearson, C. (1999). Tit for tat? The spiraling effect of incivility in the workplace. Academy of Management Review, 24, 452471.

Baron, R. A. (1988). Negative effects of destructive criticism: Impact on conflict, self-efficacy, and task performance. Journal of Applied Psychology, 73, 199-207. doi:10.1037/0021-9010.73.2.199

Barry, B., Fulmer, I. S., \& van Kleef, G. A. (2004). I laughed, I cried, I settled: The role of emotion in negotiation. In M. J. Gelfand \& J. M. Brett (Eds.), The handbook of negotiation and culture (pp. 71-94). Stanford, CA: Stanford University Press.

Baumeister, R. F., \& Leary, M. R. (1995). The need to belong: Desire for interpersonal attachments as a fundamental human motivation. Psychological Bulletin, 117, 497-529. doi:10.1037/0033-2909.117.3.497
Betancourt, H., \& Blair, I. (1992). A cognition (attribution)-emotion model of violence in conflict situations. Personality and Social Psychology Bulletin, 18, 343-350. doi:10.1177/0146167292183011

Bies, R. J., \& Tripp, T. M. (1996). Beyond distrust: "Getting even" and the need for revenge. In R. M. Kramer \& T. R. Tyler (Eds.), Trust in organizations (pp. 246-260). London, UK: Sage.

Bolger, N., DeLongis, A., Kessler, R. C., \& Schilling, A. (1989). Effects of daily stress on negative mood. Journal of Personality and Social Psychology, 57, 808-818. doi:10.1037/0022-3514.57.5.808

Bono, J., Glomb, T., Shen, W., Kim, E., \& Koch, A. (in press). Building positive resources: Effects of positive events and positive reflection on work-stress and health. The Academy of Management Journal.

Brosschot, J. F., Gerin, W., \& Thayer, J. F. (2006). The perseverative cognition hypothesis: A review of worry, prolonged stress-related physiological activation, and health. Journal of Psychosomatic Research, 60, 113-124. doi:10.1016/j.jpsychores.2005.06.074

Conner, T. S., \& Feldman Barrett, L. (2012). Trends in ambulatory selfreport: The role of momentary experience in psychosomatic medicine. Psychosomatic Medicine, 74, 327-337. doi:10.1097/PSY $.0 \mathrm{~b} 013 \mathrm{e} 3182546 \mathrm{f} 18$

Cranford, J., Shrout, P., Iida, M., Rafaeli, E., Yip, T., \& Bolger, N. (2006). A procedure for evaluating sensitivity to within-person change: Can mood measures in diary studies detect change reliably? Personality and Social Psychology Bulletin, 32, 917-929. doi:10.1177/ 0146167206287721

Crocker, J., \& Wolfe, C. T. (2001). Contingencies of self-worth. Psychological Review, 108, 593-623. doi:10.1037/0033-295X.108.3.593

Cropley, M., \& Zijlstra, F. (2011). Work and rumination. In J. Langan-Fox \& C. L. Cooper (Eds.), Handbook of stress in the occupations (pp. 487-501). Glos, UK: Edward Elgar.

De Dreu, C. K. W. (2008). The virtue and vice of workplace conflict: Food for (pessimistic) thought. Journal of Organizational Behavior, 29, 5-18. doi:10.1002/job.474

De Dreu, C. K. W., \& Beersma, B. (2005). Conflict in organizations: Beyond effectiveness and performance. European Journal of Work and Organizational Psychology, 14, 105-117. doi:10.1080/ 13594320444000227

De Dreu, C. K. W., \& Gelfand, M. J. (2008). Conflict in the workplace: Sources, functions, and dynamics across multiple levels of analysis. In C. K. W. De Dreu \& M. J. Gelfand (Eds.), The psychology of conflict and conflict management in organizations (pp. 3-54). New York, NY: Erlbaum.

De Dreu, C. K. W., Harinck, F., \& Van Vianen, A. E. M. (1999). Conflict and performance in groups and organizations. In C. L. Cooper \& I. T. Robertson (Eds.), International review of industrial and organizational psychology (Vol. 144, pp. 369-414). Chichester, UK: Wiley.

De Dreu, C. K. W., Van Dierendonck, D., \& De Best-Waldhober, M. (2003). Conflict at work and individual well-being. In M. J. Schabracq, J. A. Winnubst, \& C. L. Cooper (Eds.), Handbook of work and health psychology (2nd ed., pp. 495-515) Chichester, UK: Wiley.

De Dreu, C. K. W., \& van Knippenberg, D. (2005). The possessive self as a barrier to conflict resolution: Effects of mere ownership, process accountability, and self-concept clarity on competitive cognitions and behavior. Journal of Personality and Social Psychology, 89, 345-357. doi:10.1037/0022-3514.89.3.345

De Dreu, C. K. W., \& Weingart, L. R. (2003). Task versus relationship conflict, team performance, and team member satisfaction: A metaanalysis. Journal of Applied Psychology, 88, 741-749. doi:10.1037/ 0021-9010.88.4.741

Deutsch, M. (1973). The resolution of conflict. New Haven, CT: Yale University Press.

Dickerson, S. S., \& Kemeny, M. E. (2004). Acute stressors and cortisol responses: A theoretical integration and synthesis of laboratory research. 
Psychological Bulletin, 130, 355-391. doi:10.1037/0033-2909.130.3 .355

Edmondson, A. C. (1999). Psychological safety and learning behavior in work teams. Administrative Science Quarterly, 44, 350-383. doi: $10.2307 / 2666999$

Etzion, D., Eden, D., \& Lapidot, Y. (1998). Relief from job stressors and burnout: Reserve service as a respite. Journal of Applied Psychology, 83, 577-585. doi:10.1037/0021-9010.83.4.577

Frese, M. (1985). Stress at work and psychosomatic complaints: A causal interpretation. Journal of Applied Psychology, 70, 314-328. doi: 10.1037/0021-9010.70.2.314

Friedman, R. A., Tidd, S. T., Currall, S. C., \& Tsai, J. C. (2000). What goes around comes around: The impact of personal conflict style on work conflict and stress. International Journal of Conflict Management, 11, 32-55. doi:10.1108/eb022834

Galinsky, A. D., Maddux, W. W., Gilin, D., \& White, J. B. (2008). Why it pays to get inside the head of your opponent: The differential effects of perspective-taking and empathy in negotiations. Psychological Science, 19, 378-384. doi:10.1111/j.1467-9280.2008.02096.x

Genet, J. J., \& Siemer, M. (2012). Rumination moderates the effects of daily events on negative mood: Results from a diary study. Emotion, 12, 1329-1339. doi:10.1037/a0028070

Geurts, S. A. E., \& Sonnentag, S. (2006). Recovery as an explanatory mechanism in the relation between acute stress reactions and chronic health impairment. Scandinavian Journal of Work, Environment \& Health, 32, 482-492. doi:10.5271/sjweh.1053

Giebels, E., \& Janssen, O. (2005). Conflict stress and reduced well-being at work: The buffering effect of third-party help. European Journal of Work and Organizational Psychology, 14, 137-155. doi:10.1080/ 13594320444000236

Glasl, F. (1982). The process of escalation of conflicts and the roles of third parties. In G. B. J. Bomers \& R. Peterson (Eds.), Conflict management and industrial relations (pp. 119-140). Boston, MA: Kluwer-Nijhoff.

Guerra, J. M., Martínez, I., Munduate, L., \& Medina, F. J. (2005). A contingency perspective on the study of the consequences of conflict types: The role of organizational culture. European Journal of Work and Organizational Psychology, 14, 157-176. doi:10.1080/ 13594320444000245

Hahn, S. E. (2000). The effects of locus of control on daily exposure, coping and reactivity to work interpersonal stressors: A diary study. Personality and Individual Differences, 29, 729-748. doi:10.1016/ S0191-8869(99)00228-7

Hay, E. L., \& Diehl, M. (2010). Reactivity to daily stressors in adulthood: The importance of stressor type in characterizing risk factors. Psychology and Aging, 25, 118-131. doi:10.1037/a0018747

Hox, J. J. (2010). Multilevel analysis: Techniques and applications (2nd ed.). New York, NY: Routledge.

Huffziger, S., Ebner-Priemer, U., Koudela, S., Reinhard, I., \& Kuehner, C. (2012). Induced rumination in everyday life: Advancing research approaches to study rumination. Personality and Individual Differences, 53, 790-795. doi:10.1016/j.paid.2012.06.009

Ilies, R., Dimotakis, N., \& de Pater, I. E. (2010). Psychological and physiological reactions to high workloads: Implications for well-being. Personnel Psychology, 63, 407-436. doi:10.1111/j.1744-6570.2010 .01175.x

Ilies, R., Johnson, M. D., Judge, T. A., \& Keeney, J. (2011). A withinindividual study of interpersonal conflict as a work stressor: Dispositional and situational moderators. Journal of Organizational Behavior, 32, 44-64. doi:10.1002/job.677

Ilies, R., Schwind, K. M., \& Heller, D. (2007). Employee well-being: A multilevel model linking work and nonwork domains. European Journal of Work and Organizational Psychology, 16, 326-341. doi:10.1080/ 13594320701363712
Jehn, K. A. (1995). A multimethod examination of the benefits and detriments of intragroup conflict. Administrative Science Quarterly, 40, 256-282. doi:10.2307/2393638

Jehn, K. A., \& Chatman, J. A. (2000). The influence of proportional and perceptual conflict composition on team performance. International Journal of Conflict Management, 11, 56-73. doi:10.1108/eb022835

Jensen-Campbell, L. A., \& Graziano, W. G. (2000). Beyond the school yard: Relationships as moderators of daily interpersonal conflict. Personality and Social Psychology Bulletin, 26, 923-935. doi:10.1177/ 01461672002610003

Kamarck, T. W., Schwartz, J. E., Shiffman, S., Muldoon, M. F., SuttonTyrrell, K., \& Janicki, D. L. (2005). Psychosocial stress and cardiovascular risk: What is the role of daily experience? Journal of Personality, 73, 1749-1774. doi:10.1111/j.0022-3506.2005.00365.x

Lazarus, R. S. (1991). Emotion and adaptation. New York: Oxford University Press.

Lazarus, R. S. (1999). Stress and emotion: A new synthesis. New York, NY: Springer.

Martin, L. L., \& Tesser, A. (1996). Some ruminative thoughts. In R. S. Wyer (Ed.), Ruminative thoughts (pp. 1-47). Mahwah, NJ: Erlbaum.

McEwen, B. S. (1998). Protective and damaging effects of stress mediators. New England Journal of Medicine, 338, 171-179. doi:10.1056/ NEJM199801153380307

McNair, D. M., Lorr, M., \& Droppleman, L. F. (1992). Edits manual for the Profile of Mood States. San Diego, CA: Educational and Industrial Testing Service.

Meier, L. L., Semmer, N. K., \& Hupfeld, J. (2009). The impact of unfair treatment on depressive mood: The moderating role of self-esteem level and self-esteem instability. Personality and Social Psychology Bulletin, 35, 643-655. doi:10.1177/0146167208331337

Meijman, T. F., \& Mulder, G. (1998). Psychological aspects of workload. In P. J. D. Drenth, H. Thierry, \& C. J. de Wolff (Eds.), Handbook of work and organizational psychology (Vol. 2, pp. 5-33). East Sussex, UK: Psychology Press.

Mitchell, T. R., \& James, L. R. (2001). Building better theory: Time and the specification of when things happen. Academy of Management Review, 26, 530-547.

Mohr, G. (1986). Die Erfassung psychischer Befndensbeeinsträchtigungen bei Arbeitern [The measurement of mental deterioration of blue-collar workers]. Frankfurt/Main, Germany: Peter Lang.

Muthén, L. K., \& Muthén, B. O. (2010). Mplus user's guide (6th ed.). Los Angeles, CA: Author

Nezlek, J. B. (2007). Multilevel modeling in research on personality. In R. Robins, R. C. Fraley, \& R. Krueger (Eds.), Handbook of research methods in personality psychology (pp. 502-523). New York, NY: Guilford Press.

Nezlek, J. B. (2011). Multilevel modeling for social and personality psychology. London, UK: Sage.

Nixon, A. E., Mazzola, J. J., Bauer, J., Krueger, J. R., \& Spector, P. E. (2011). Can work make you sick? A meta-analysis of the relationships between job stressors and physical symptoms. Work \& Stress, 25, 1-22. doi:10.1080/02678373.2011.569175

Pearson, C., Andersson, L., \& Wegner, J. W. (2001). When workers flout convention: A study of workplace incivility. Human Relations, 54, 1387-1419. doi:10.1177/00187267015411001

Pinkley, R. L. (1990). Dimensions of conflict frame: Disputant interpretations of conflict. Journal of Applied Psychology, 75, 117-126. doi: 10.1037/0021-9010.75.2.117

Pondy, L. R. (1992). Reflections on organizational conflict. Journal of Organizational Behavior, 13, 257-261. doi:10.1002/job.4030130305

Porath, C., \& Erez, A. (2007). Does rudeness really matter? The effects of rudeness on task performance and helpfulness. The Academy of Management Journal, 50, 1181-1197. doi:10.2307/20159919 
Preacher, K., Curran, P., \& Bauer, D. (2006). Computational tools for probing interactions in multiple linear regression, multilevel modeling, and latent curve analysis. Journal of Educational and Behavioral Statistics, 31, 437-448. doi:10.3102/10769986031004437

Querstret, D., \& Cropley, M. (2012). Exploring the relationship between work-related rumination, sleep quality, and work-related fatigue. Journal of Occupational Health Psychology, 17, 341-353. doi:10.1037/ a0028552

Raudenbush, S. W., Bryk, A. S., Cheong, Y. K., \& Congdon, R. T., Jr. (2004). HLM 6: Hierarchical linear and nonlinear modeling (Version 6.06) [Computer software]. Lincolnwood, IL: Scientific Software International.

Ray, R. D., Wilhelm, F. H., \& Gross, J. J. (2008). All in the mind's eye? Anger rumination and reappraisal. Journal of Personality and Social Psychology, 94, 133-145. doi:10.1037/0022-3514.94.1.133

Repetti, R., Wang, S., \& Saxbe, D. (2009). Bringing it all back home. How outside stressors shape families' everyday lives. Current Directions in Psychological Science, 18, 106-111. doi:10.1111/j.1467-8721.2009 .01618.x

Semmer, N. K., Jacobshagen, N., Meier, L. L., \& Elfering, A. (2007). Occupational stress research: The "stress-as-offense-to-self" perspective. In J. Houdmont \& S. McIntyre (Eds.), Occupational health psychology: European perspectives on research, education and practice (Vol. 2, pp. 43-60). Castelo da Maia, Portugal: ISMAI Publishing.

Shah, P. P., \& Jehn, K. A. (1993). Do friends perform better than acquaintances? The interaction of friendship, conflict, and task. Group Decision and Negotiation, 2, 149-165. doi:10.1007/BF01884769

Shaver, K. G. (1985). The attribution of blame: Causality, responsibility, and blameworthiness. New York, NY: Springer. doi:10.1007/978-14612-5094-4

Simons, T. L., \& Peterson, R. S. (2000). Task conflict and relationship conflict in top management teams: The pivotal role of intragroup trust. Journal of Applied Psychology, 85, 102-111. doi:10.1037/0021-9010.85 .1 .102

Sonnentag, S. (2012). Psychological detachment from work during leisure time: The benefits of mentally disengaging from work. Current Directions in Psychological Science, 21, 114-118. doi:10.1177/ 0963721411434979

Sonnentag, S., \& Fritz, C. (2007). The Recovery Experience Questionnaire: Development and validation of a measure for assessing recuperation and unwinding from work. Journal of Occupational Health Psychology, 12, 204-221. doi:10.1037/1076-8998.12.3.204

Sonnentag, S., Kuttler, I., \& Fritz, C. (2010). Job stressors, emotional exhaustion, and need for recovery: A multi-source study on the benefits of psychological detachment. Journal of Vocational Behavior, 76, 355365. doi:10.1016/j.jvb.2009.06.005

Sonnentag, S., Unger, D., \& Nägel, I. J. (in press). Workplace conflict and employee well-being: The moderating role of detachment from work during off-job time. International Journal of Conflict Management.

Spector, P. E., \& Bruk-Lee, V. (2008). Conflict, health, and well-being. In C. K. W. De Dreu \& M. J. Gelfand (Eds.), The psychology of conflict and conflict management in organizations (pp. 267-288). San Francisco, CA: Jossey-Bass.

Spector, P. E., \& Jex, S. M. (1998). Development of four self-report measures of job stressors and strain: Interpersonal Conflict at Work Scale, Organizational Constraints Scale, Quantitative Workload Inventory, and Physical Symptoms Inventory. Journal of Occupational Health Psychology, 3, 356-367. doi:10.1037/1076-8998.3.4.356

Tjosvold, D. (2008). The conflict-positive organization: It depends upon us. Journal of Organizational Behavior, 29, 19-28. doi:10.1002/job.473

Treynor, W., Gonzalez, R., \& Nolen-Hoeksema, S. (2003). Rumination reconsidered: A psychometric analysis. Cognitive Therapy and Research, 27, 247-259. doi:10.1023/A:1023910315561

Van de Vliert, E. (1997). Complex interpersonal conflict behaviour. Hove, UK: Psychology Press.

Van de Vliert, E., \& De Dreu, C. K. W. (1994). Optimizing performance by stimulating conflict. International Journal of Conflict Management, 5, 211-222. doi:10.1108/eb022743

Van Kleef, G. A. (2009). How emotions regulate social life: The emotions as social information (EASI) model. Current Directions in Psychological Science, 18, 184-188. doi:10.1111/j.1467-8721.2009.01633.x

Volmer, J., Binnewies, C., Sonnentag, S., \& Niessen, C. (2012). Do social conflicts with customers at work encroach upon our private lives? A diary study. Journal of Occupational Health Psychology, 17, 304-315. doi:10.1037/a0028454

Watson, D., Pennebaker, J. W., \& Folger, R. (1987). Beyond negative affectivity: Measuring stress and satisfaction in the workplace. Journal of Organizational Behavior Management, 8, 141-157. doi:10.1300/ J075v08n02_09

Weiner, B. (1985). An attributional theory of achievement motivation and emotion. Psychological Review, 92, 548-573. doi:10.1037/0033-295X .92 .4 .548

Received April 16, 2012

Revision received January 29, 2013

Accepted February 1, 2013 